\title{
Somatostatin in the Pontine Reticular Formation Modulates Fear Potentiation of the Acoustic Startle Response: An Anatomical, Electrophysiological, and Behavioral Study
}

\author{
Markus Fendt, Michael Koch, and Hans-Ulrich Schnitzler \\ Tierphysiologie, Universilät Tübingen, D-72076 Tübingen, Germany
}

The amplitude of the acoustic startle response (ASR) in rats is increased in the presence of a cue that has previously been paired with an aversive stimulus such as a footshock. This phenomenon is called fear-potentiated startle and is a model to study the neuronal and neurochemical mechanisms of the acquisition and expression of fear. The present study investigated the role in fear-potentiated startle of somatostatin in the caudal pontine reticular nucleus $(\mathrm{PnC})$ by a combination of anatomical, electrophysiological, and behavioral methods. The $\mathrm{PnC}$ is an essential part of the primary startle circuit and is also the recipient of modulatory influences. First, we showed that the central gray (CG), which is involved in fear conditioning, is the main source of somatostatinergic input to the PnC. In the second experiment, we iontophoretically applied the somatostatin receptor agonist sandostatin on $\mathrm{PnC}$ neurons and extracellularly recorded the activity of $\mathrm{PnC}$ neurons. Sandostatin had no effect on tone-evoked or spontaneous activity, but markedly attenuated the increase of neuronal activity seen after the administration of glutamate. In our third experiment, we injected different doses of sandostatin into the PnC of awake rats. Sandostatin blocked fear potentiation of the ASR but had no effect on the baseline ASR amplitude. The present study indicates that the somatostatinergic projection from the CG to the $\mathrm{PnC}$ is important for the modulation of fear-potentiated startle. We present a possible neural circuitry for the expression of fear-potentiated startle based on these data and previous findings.

Key words: acoustic startle response; amygdala; anxiety; caudal pontine reticular nucleus; central gray; fear; neuropeptides; periaqueductal gray; sandostatin; SMS 201-995; somatostatin; rat
Fear and anxiety are important determinants of the behavior of higher vertebrates. Therefore, a variety of studies have addressed the neuronal basis of states of fear in mammals. One of the most successful models to investigate the neural basis of fear is the fear-potentiated startle paradigm (Davis et al., 1993). A series of experiments using the fear-potentiated startle paradigm reveded that the amygdala plays an important role in the acquisition of the conditioned stimulus (CS) (Davis, 1992a,b). For the expression of conditioned fear in the potentiated startle paradigm, several parallel pathways from the amygdala to the caudal pontine reticular formation (PnC) are responsible (Hitchcock and Davis, 1991; Fendt et al., 1996). The PnC is a crucial part of the primary startle circuit acting as a sensorimotor relay nucleus between the sensory input and the motor output (Davis et al., 1982; Koch et al., 1992; Lingenhöhl and Friauf, 1992, 1994). The PnC also receives a number of inputs from different brain nuclei, many of which are responsible for down- or upmodulation of the acoustic startle response (ASR) (Rosen et al., 1991; Koch and Ebert, 1993; Koch et al., 1993; Frankland et al., 1995; Fendt et al., 1996). In the present study, we focused on the enhancement of the ASR amplitude by conditioned fear. When an initially neutral stimulus such as a light is repeatedly paired with an aversive stimulus such

Received Dec. 11, 1995; revised Feb. 5, 1996; accepted Feb. 9, 1996.

This work was supported by the Deutsche Forschungsgemeinschaft (SFB 307/C2 and C3) and the Graduiertenkolleg Neurobiologie Tübingen. We are grateful to Dr. Joachim Ostwald, Christian Felsheim, Martin Kungel, Karsten Feil, and Helga Zillus for their various kinds of help. We also thank Sandoz AG, Basel, Switzerland, for the gift of sandostatin.

Correspondence should be addressed to Markus Fendt, Tierphysiologie, Universität Tübingen, Auf der Morgenstelle 28, D-72076 Tübingen, Germany. Copyright $\mathbb{C} 1996$ Society for Neuroscience $0270-6474 / 96 / 163097-07 \$ 05.00 / 0$ as an electric footshock, the light alone predicts the occurrence of the shock and acts as a conditioned aversive stimulus, which elicits a state of fear, indicated by an enhancement or potentiation of the ASR amplitude. Recent experimental work has led to the assumption that there are at least four separate pathways from the amygdala to the $\mathrm{PnC}$, which are all necessary for the enhancement of the ASR: one direct pathway from the amygdala to the $\mathrm{PnC}$ (Hitchcock and Davis, 1991; Rosen et al., 1991; Koch and Fhert, 1993) and indirect pathways via the CG (Fendt et al., 1994; Fendt et al., 1996), the rostrolateral midbrain (Yeomans and Pollard, 1993; Frankland and Yeomans, 1995), and the laterodorsal tegmental nucleus (Krase et al., 1994; Kungel et al., 1994).

One of the primary aims of our recent work is to differentiate these pathways. This endeavor includes the identification and neurochemical characterization of the different inputs to the PnC. One candidate for a neurotransmitter that could play a role in the mediation of conditioned fear within these pathways is the tetradecapeptide somatostatin. Somatostatin is widely distributed in the brain, but it is particularly concentrated in the amygdaloid nuclei, the CG, the parabrachial nuclei, the hypothalamus, and the nucleus of the solitary tract (Palkovits and Brownstein, 1985; Rubinow et al., 1995). Because both the amygdala and the CG project to the PnC and play a crucial role in the mediation of conditioned fear, we tested the hypothesis that a somatostatinergic projection (from the amygdala and/or the CG) to the $\mathrm{PnC}$ is involved in the mediation of fear-potentiated startle.

To test this hypothesis, we first investigated which of the afferents to the PnC contain somatostatin as a transmitter. Then we examined the effects of the specific somatostatin receptor agonist sandostatin on the tone-evoked activity of single PnC neurons. In 
the third part of our study, we injected sandostatin into the PnC of awake rats, and subsequently measured the effects on the ASR amplitude and fear-potentiated startle.

\section{MATERIALS AND METHODS}

\section{Double-labeling experiments}

Three male Wistar rats (200-260 gm) were anesthetized with chloral hydrate $(420 \mathrm{mg} / \mathrm{kg}$, i.p.), and the retrograde tracer Fluoro Gold was injected iontophoretically under stereotaxic control into the $\mathrm{PnC}$. The details of this procedure have been described elsewhere (Koch and Ebert, 1993; Koch et al., 1993). After a survival time of 1 week, the animals were anesthetized and received colchicine injections (150 ng in $10 \mu \mathrm{l}$ of saline) into the fourth ventricle. After $30 \mathrm{hr}$, the rats were reanesthetized and perfused through the ascending aorta with $0.1 \mathrm{~m}$ PRS followed by cold $4 \%$ paraformaldehyde in $0.1 \mathrm{M}$ phosphate buffer. The brains were placed in $20 \%$ sucrose in PBS until they sank. Coronal sections of $40 \mu \mathrm{m}$ were taken on a freezing microtome and divided into two series: one scries was Nissl-stained with thionine, and the second series was used for somatostatin immunohistochemistry and to analyze retrogradely labeled neurons.

We applied the same methodology as Kungel and Friauf (1995) to visualize neurons containing the neuropeptide somatostatin. Briefly, sections were washed in Tris-buffered saline (TBS; $\mathrm{pH}$ 7.6) and preincubated for $1 \mathrm{hr}$ with $10 \%$ goat serum in TBS with $0.3 \%$ Triton X-100. Then the sections were transferred into the primary antiserum, which contained rabbit anti-somatostatin antiserum (Peninsula Labs: RIK 8001; dilution 1:1000), incubated at $4^{\circ} \mathrm{C}$ overnight, washed several times in TBS, and incubated in a tetramethylrhodamine isothiocyanate-conjugated secondary antiserum (Dako Diagnostika, Hamburg, Germany) for $1.5 \mathrm{hr}$. After washing them thoroughly, the sections were mounted on gelatin-coated slides and allowed to air dry overnight.

All sections were dehydrated in an ascending scries of cthanols, clcared in xylene, and coverslips were applied using DPX. For data analysis, representative sections were analyzed under a Reichert-Jung microscope using epifluorescent illumination and different filters for the fluorescent sections.

\section{Electrophysiology}

Nine male Wistar rats were anesthetized with urethane $(2 \mathrm{gm} / \mathrm{kg}$, i.p.). The caudal part of the skull was opened and parts of the cerebellum were aspirated to expose the brainstem. Teflon-insulated tungsten electrodes (impedance: $10 \mathrm{M} \Omega$ ) were used for extracellularly recording the electrical activity of the $\mathrm{PnC}$, and multibarreled glass pipettes (tip diameter 3-5 $\mu \mathrm{m}$, glued to the recording electrodes, tips separated by $30-100 \mu \mathrm{m}$ ) were used for drug application. Barrels were filled with sandostatin $(0.1 \mathrm{mM}$, pH 9.0; SMS 201-995, Sandoz, Basel, Switzerland) and sodium glutamate (500 mM, pH 7.4; Sigma, Deisenhofen, Germany). The drugs were ejected microiontophoretically by a programmable constant-current source (custom-made at McGill University, Montreal, Canada) with negative currents up to $80 \mathrm{nA}$. The electrode was lowered into the $\mathrm{PnC}$ under stereotaxic control by a hydraulic microdrive. The acoustic stimuli were delivered through a loudspeaker, mounted at a distance of $10 \mathrm{~cm}$ in front of the rat's head. Tone pulses of $10 \mathrm{kHz}, 110 \mathrm{~dB}$ sound pressure level (SPL), $50 \mathrm{msec}$ duration (including $0.4 \mathrm{msec}$ rise and fall times) were presented at a rate of $0.8 \mathrm{~Hz}$.

Peristimulus time histograms (PSTHs) from 50 consecutive stimuli were calculated on-line by a computer. Spike rates were calculated from the PSTHs. Spikes occurring in the time frame $50 \mathrm{msec}$ before acoustic stimulation were taken as spontaneous activity, and the spikes occurring in the time frame of the acoustic stimulus $(50 \mathrm{msec})$ were taken as the tone-evoked activity. Statistical analysis was performed by ANOVA, post hoc Tukey test, and Wilcoxon signed-rank test. For all statistical comparisons, a $p<0.05$ was taken as the criterion for statistical significance.

\section{Behavioral studies}

A total of 23 male Wistar rats, weighing $200-280 \mathrm{gm}$ at the beginning of the experiments, were used for the behavioral tests. They were housed in groups of 5-6 animals under a continuous light/dark cycle (lights on from 7:00 A.M. to 7:00 P.M.). Food and water were freely available.

The animals were anesthetized with chloral hydrate $(420 \mathrm{mg} / \mathrm{kg}$, i.p.) and placed in a stereotaxic frame. Two 23-gauge stainless steel guide cannulae were implanted bilaterally into the brain aimed at the PnC [ $-9.8 \mathrm{~mm}$ caudal, $\pm 0.8 \mathrm{~mm}$ lateral, $-9.3 \mathrm{~mm}$ ventral from bregma, according to the coordinates of Paxinos and Watson (1986)]. The guide cannulae were fixed to the skull with dental cement and three anchoring screws. After surgery and between the experiments, stylets were inserted into the guide cannulae to maintain patency. The animals were allowed to recover from surgery for 1 week. They were handled $2 \mathrm{~d}$ before testing began.

Effect of sandostatin injections on the ASR amplitude. To measure the ASR amplitude, the rats were placed in a wire mesh cage $(20 \times 10 \times 12$ $\mathrm{cm}^{3}$ ) mounted on a piezoelectric accelerometer (custom-made at the University of Tübingen), which was located inside a sound-attenuated chamber $\left(100 \times 80 \times 60 \mathrm{~cm}^{3}\right)$. Movements of the rats resulted in changes of the voltage output of the accelerometer. These signals were amplified, digitized, and fed into a computer for further analysis. The presentation of the acoustic stimuli was also controlled by a microcomputer and an appropriate interface (Hortmann universal function synthesizer). A loudspeaker mounted $40 \mathrm{~cm}$ from the wire mesh cage delivered the acoustic startle stimuli and a continuous white background noise (55 dB SPL, root mean square). The whole-body startle amplitude was calculated from the difference between the peak-to-peak voltage output of the accelerometer within time windows of $80 \mathrm{msec}$ after and $80 \mathrm{msec}$ before the startle stimulus onset.

After an adaptation time of $5 \mathrm{~min}$, during which no startle stimuli were presentcd except for a continuous background noisc of $55 \mathrm{~dB}$ SPL, the animals received 40 startle stimuli presented at an interstimulus interval of $30 \mathrm{sec}$. Then the rats were injected with sandostatin $(\mathrm{pH}=7.4)$ or vehicle (saline, $\mathrm{pH}=7.4$ ) bilaterally into the $\mathrm{PnC}$ through 30-gauge stainless steel injection cannulae. Each animal received $0,0.25,0.5$, or 1 nmol of sandostatin on four subsequent days in a randomized order. The injection volume was $0.5 \mu \mathrm{l}$ and the injection rate was $0.1 \mu \mathrm{l} / 5 \mathrm{sec}$. The injection cannulae remained in the brain during the test. An additional 40 startle stimuli were presented after drug injection. The effect of an injection was calculated as the mean percent change of the ASR amplitude (difference between the peak-to-peak amplitude in the $80 \mathrm{msec}$ time windows before and after the startle stimulus) of 20 trials after the injection compared with the 20 trials before the injection.

Effect of sandostatin injections on fear conditioning. The rats were traincd in a dark box $\left(38 \times 60 \times 28 \mathrm{~cm}^{3}\right)$, the sides and the top of which were covered with black cardboard. The floor was composed of steel bars spaced $\sim 15 \mathrm{~mm}$ apart. The CS was a white light produced by a $40 \mathrm{~W}$ bulb located at the top of the box. The unconditioned stimulus (US) was a 0.6 $\mathrm{mA}$ footshock produced by a shock generator (custom-made at the University of Tübingen) located outside the chamber. The animals were placed into the training box and after an acclimation time of $5 \mathrm{~min}$, they received 10 pairings of the light $\mathrm{CS}$ and footshock US. The US was presented during the last $0.5 \mathrm{sec}$ of the $3.7 \mathrm{sec}$ light $\mathrm{CS}$ at an average intertrial interval of $3 \mathrm{~min}$ (range 2-4 min). After an initial training session on day 1 (10 pairings), the animals were tested for the effects of different doses of sandostatin in a randomized order on four subsequent days. To avoid extinction of fear conditioning during testing, the animals were retrained once daily $3 \mathrm{hr}$ before testing. Retraining and initial training procedures were identical.

To test fear-potentiated startle, the rats were placed in the startle chamber. After 5 min of adaptation, 10 acoustic startle stimuli $(100 \mathrm{~dB}$ SPL, $20 \mathrm{msec}$ duration including $0.4 \mathrm{msec}$ rise and fall times, $30 \mathrm{sec}$ interstimulus interval) were presented to obtain a baseline ASR amplitude. The injection of sandostatin $(0,0.25,0.5$, or $1 \mathrm{nmol})$ was given after the fifth startle stimulus as described above. After the 10 initial startle stimuli, each animal received 40 acoustic startle stimuli with half of the stimuli presented in darkness (tone alone trials) and the other half presented $3.2 \mathrm{sec}$ after the onset of the $3.7 \mathrm{sec}$ light CS (light-tone trials). The two trial types were presented in a randomized order.

After the tests, the animals were killed by an overdose of nembutal. The animals were decapitated, and their brains were removed and immersion-fixed with $8 \%$ paraformaldehyde in PBS with $20 \%$ sucrose. Coronal sections of $60 \mu \mathrm{m}$ were taken on a freezing microtome and stained with cresyl violet. The injection sites were drawn onto plates taken from the atlas of Paxinos and Watson (1986).

Statistical analysis of the data were accomplished by ANOVA. For all statistical comparisons, a $p<0.05$ was taken as the criterion for statistical significance.

\section{RESULTS}

\section{Double-labeling experiments}

A codistribution of retrogradely labeled neurons and somatostatin-like immunoreactive neurons was found in the cochlear nucleus, the laterodorsal tegmental nucleus, the $\mathrm{CG}$, the 
Table 1. Effects of microiontophoretically applied sandostatin and glutamate on the activity of PNC neurons

\begin{tabular}{lcl} 
Treatment & $\begin{array}{l}\text { Tone-evoked activity } \\
\text { (number of spikes) }\end{array}$ & $\begin{array}{l}\text { Spontaneous activity } \\
\text { (number of spikes) }\end{array}$ \\
\hline Control & $75 \pm 8$ & $14 \pm 5$ \\
Sandostatin & $77 \pm 9$ & $15 \pm 5$ \\
Glutamate & $146 \pm 13^{*}$ & $61 \pm 10^{*}$ \\
$\begin{array}{l}\text { Sandostatin }+ \\
\quad \text { Glutamate }\end{array}$ & $94 \pm 7^{\circ *}$ & $22 \pm 4^{\circ}$
\end{tabular}

${ }^{*} p<0.01$ Significantly different from control treatment.

${ }^{\circ} p<0.01$ Significantly different from glutamate treatment.

Post hoc Tukey tests after an ANOVA.

lateral hypothalamus, the central nucleus of the amygdala, the zona incerta, the substantia nigra, and the sensory trigeminal nucleus. Double-labeled cells were only seen at high levels $(\sim 20 \%$ of the retrogradely labeled cells and $35 \%$ of the somatostatin-like immunoreactive cells) in the lateral and ventral parts of the CG (Fig. 1) and at low levels $(<10 \%)$ in the subcoeruleus nucleus and the sensory trigeminal nucleus. In the present study, we focused only on projections to the $\mathrm{PnC}$ that have previously been shown to be involved in the modulation of the ASR by conditioned fear. In the central nucleus of the amygdala and the laterodorsal tegmental nucleus, no double-labeled cells were observed. This staining pattern was similar in all three cases.

Retrograde-labeled neurons were also found in the superior olivary complex, the pedunculopontine tegmental nuclei, the colliculus superior, the deep mesencephalic nuclei, the basal nucleus of Meynert, and different parts of the medullary and mesencephalic reticular formation, as described in previous studies (Shammah-Lagnado et al., 1987; Rosen et al., 1991; Koch and Ebert, 1993; Koch et al., 1993; Fendt et al., 1994). Furthermore, high levels of somatostatin-like immunoreactive neurons were found in the different nuclei of the amygdala, the cortex, the parabrachial nuclei, and the nucleus of the solitary tract. Lower levels were found in the periolivary region, the oral and caudal $\mathrm{PnC}$, and the hippocampus. This distribution resembles the ones described previously (Palkovits and Brownstein, 1985; Kungel and Friauf, 1995; Rubinow et al., 1995).

\section{Electrophysiology}

Recordings were obtained from 17 acoustically responsive single units. Histological analysis revealed that these units were all located in the PnC. Usually, these units responded with a minimal latency of 2-6 msec, had no or only a low spontaneous activity, and the tone-evoked response consisted of a prominent onset peak followed by low sustained activity.

Using ejection currents of $50 \pm 4 \mathrm{nA}$, the tone-evoked activity was not significantly affected by sandostatin (Wilcoxon: $z=-1.19, p=0.23)$. Ten units showed a small increase of their mean tone-evoked number of spikes from $74 \pm 11$ to $81 \pm 12$ (average of $8.6 \pm 1.4 \%$ ), five units showed a trend of decrease of their mean tone-evoked activity from $73 \pm 15$ to $67 \pm 16$ (average of $9.7 \pm 5.0 \%$ ), and two units showed no changes after sandostatin application. In Table 1 , the mean number of toneevoked spikes of all 17 units is shown. The spontaneous activity was not affected by sandostatin (see Table 1; Wilcoxon: $z=$ $-0.51, p=0.61)$.

To test whether sandostatin had an effect on the glutamateevoked increase of neuronal activity, we coadministered glutamate and sandostatin. Glutamate alone significantly enhanced the
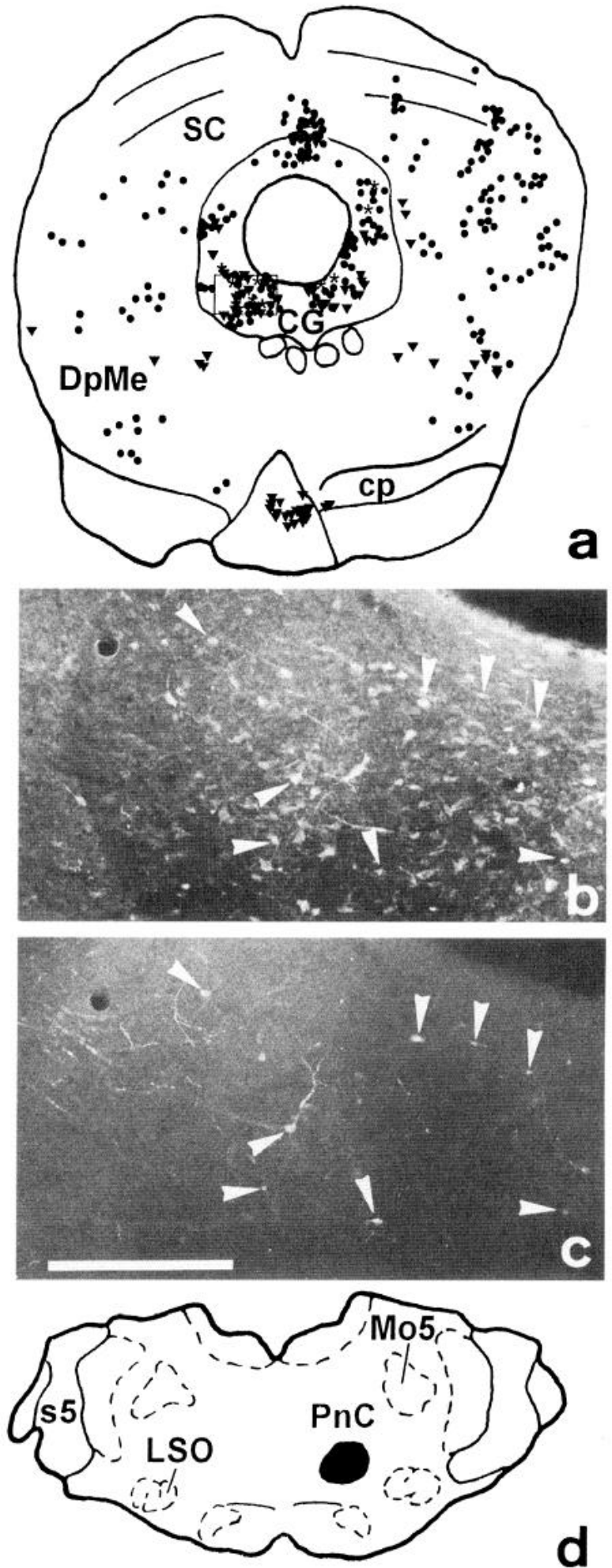

Figure 1. $a$, Line drawing of a representative coronal section through the CG illustrating retrogradely labeled cells (dots) after Fluoro Gold injection into the PnC, somatostatin-like immunoreactive cells (triangles), and double-labeled cells (asterisks). One triangle represents 2-4 somatostatinlike immunoreactive cells. The framed area in $a$ is enlarged in $b$ and $c$ showing fluorescence photomicrographs through the CG with somatostatinergic cells $(b)$ and retrogradely labeled cells $(c)$ after Fluoro Gold injections into the PnC. The double-labeled neurons are indicated by arrowheads. $d$, Line drawing of a coronal section showing the injection site of Fluoro Gold in the PnC. $C G$, Central gray; $c p$, cerebral peduncle; $D p M e$, deep mesencephalic nuclei; LSO, lateral superior olive; Mo5, motor trigeminal nucleus; $P n C$, caudale pontine reticular nucleus; $S C$, superior colliculus; $s 5$, sensory root trigeminal nerve. Scale bar, $250 \mu \mathrm{m}$. 

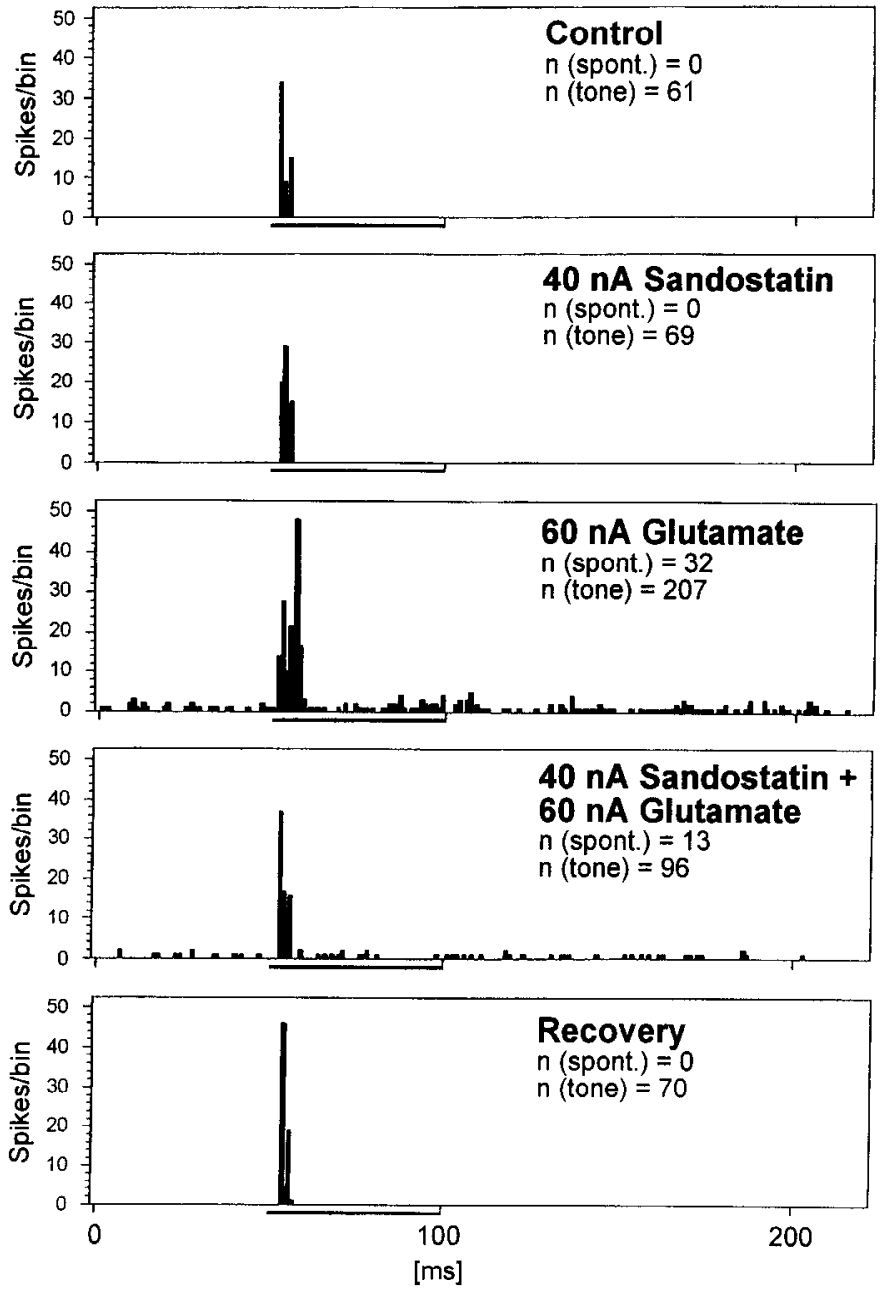

Figure 2. Peristimulus time histograms showing the effect of sandostatin and glutamate on the acoustically evoked and spontaneously occurring action potentials of a PnC neuron. Bin width: $1 \mathrm{msec}$. Black bar represents the acoustic stimulus. The total number $(n)$ of spontaneous $(0-50 \mathrm{msec})$ and tone-evoked $(50-100 \mathrm{msec})$ spikes are calculated and given in each histogram.

tone-evoked activity of all units by an average of $105.8 \pm 15.2 \%$ (see Table 1; Wilcoxon: $z=-3.62, p=0.0003$ ). The spontaneous activity was also clearly increased (see Table 1; Wilcoxon: $z=$ $-3.59, p=0.0003$ ). If sandostatin was coapplied with glutamate, the glutamate effect was significantly attenuated in all units by an average of $-69.4 \pm 6.8 \%$ (Wilcoxon: $z=-3.62, p=0.0003$ ). The fact that the tone-evoked activity after sandostatin-glutamate application was still higher than under control conditions (see Table 1) indicates that the glutamate effect was not totally blocked by sandostatin. The spontaneous neuronal activity, which was increased after glutamate application, was similar to the control condition after coapplication of sandostatin (see Table 1), indicating that the effect of glutamate on spontaneous activity was totally blocked by sandostatin.

Figure 2 shows a typical response of a PnC neuron to acoustic stimulation, with no effect of sandostatin application, a clear increase of the onset response and the spontaneous activity induced by the administration of glutamate, and an attenuation of the glutamate effect by sandostatin.

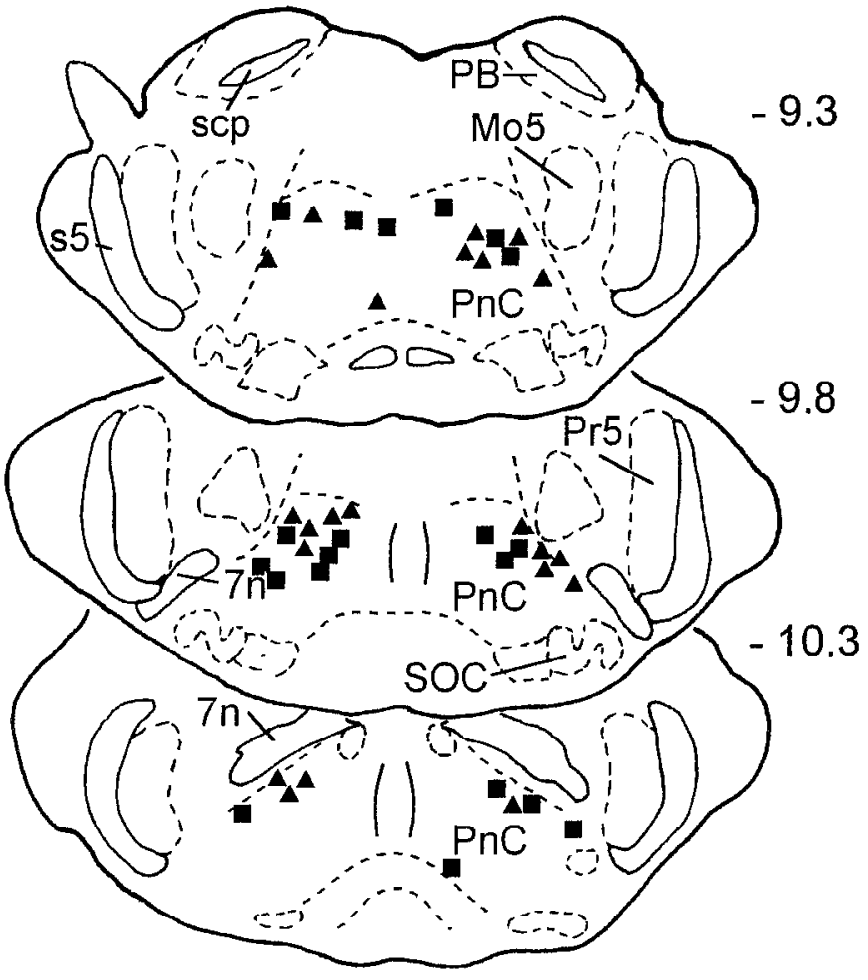

Figure 3. Serial drawings of coronal sections through the lower brainstem depicting the injection sites of sandostatin (squares: test of the drug effects on ASR baseline; triangles: test of fear-potentiated startle). $7 n$, Facial nerve; $M o 5$, motor trigeminal nucleus; $P B$, parabrachial nucleus; $P n C$, caudal pontine reticular nucleus; $\operatorname{Pr} 5$, principal sensory trigeminal nucleus; $s 5$, sensory root of the trigeminal nerve; $s c p$, superior cerebellar peduncle; $S O C$, superior olivary complex.

\section{Behavioral studies}

\section{Effect of sandostatin injections on the ASR amplitude}

Eleven rats received bilateral injections of sandostatin into the PnC. The injection sites of these rats are shown in Figure 3. No significant differences were found between the preinjection ASR amplitudes (ANOVA: $F_{(3,44)}=0.14, p=0.93$ ). The percent difference scores between the pre- and the postinjection ASR amplitudes show no statistically significant differences (Figure 4; ANOVA: $\left.F_{(3,44)}=0.10, p=0.96\right)$, indicating that injections of sandostatin into the $\mathrm{PnC}$ did not affect the baseline ASR amplitude.

\section{Effect of sandostatin injections on fear conditioning}

Twelve rats sustained fear conditioning and received bilateral injections of sandostatin into the $\mathrm{PnC}$ (injection sites are shown in Fig. 3). Figure 5 shows the mean ASR amplitudes on the tone and light-tone trials after injections of saline or sandostatin, along with the corresponding difference scores. All of these animals showed a significantly potentiated ASR in the presence of the CS after injections of saline ( $t$ test: $t=5.08 ; p=0.0005$ ). The ASR amplitude on tone-alone trials showed no drug effects (ANOVA: $F_{(3,41)}=0.50, p=0.69$ ), consistent with the findings of the previous experiment. However, after injections of sandostatin into the $\mathrm{PnC}$ no significant differences between tone and light-tone trials were observed ( $p$ values $>0.05, t$ tests), indicating that sandostatin blocked the fear potentiation of the ASR over a wide dosage range. An ANOVA on the difference scores showed a significant effect of sandostatin $\left(F_{(3,41)}=3.21, p=0.03\right)$. Post hoc Tukey tests show $p$ values $<0.05$ for the pairwise comparisons 


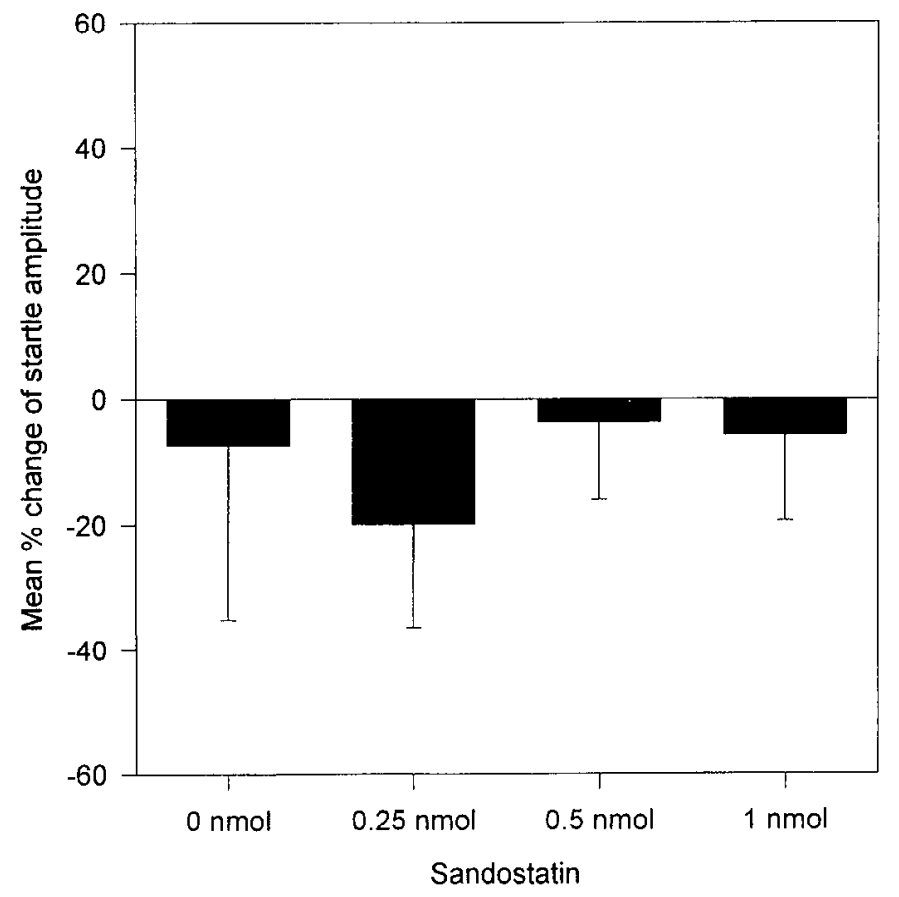

Figure 4. Bar diagram showing the effects on the ASR of local microinjections of sandostatin (or saline) into the PnC. The mean percent change ( \pm SEM) of the ASR amplitude (arbitrary units) after drug injection is plotted.

between the difference scores after saline injections and the difference scores after local application of $0.25,0.5$, or $1 \mathrm{nmol}$ sandostatin.

\section{DISCUSSION}

The present study tested the hypothesis that a somatostatinergic projection to the PnC is involved in the modulation of the ASR by conditioned fear. It represents one of several studies that are currently under way in our laboratory to investigate the roles of different projections to the primary startle pathway in the modulation of the ASR by fear and anxiety.

Our anatomical data demonstrate a strong somatostatinergic projection from the lateral and ventral part of the CG to the PnC. The central nucleus of the amygdala and the laterodorsal tegmental nucleus, two other $\mathrm{PnC}$ afferents involved in the enhancement of the ASR (Davis, 1992b; Davis et al., 1993; Krase et al., 1994; Kungel et al., 1994), obviously do not use somatostatin as a transmitter for projection to the $\mathrm{PnC}$. The $\mathrm{PnC}$ also receives two weak somatostatinergic projections from the subcoeruleus nucleus and the sensory trigeminal nucleus, but to our knowledge, an implication of these nuclei in the modulation of the ASR has not been shown. Other somatostatinergic projections to the PnC were not evident in our histological material and are not known from the literature. Rubinow and coworkers (1995) reviewed the main somatostatinergic pathways in the brain: there are projections from the periventricular nucleus to the median eminence, from different hypothalamic nuclei to limbic structures (e.g., amygdala and the stria terminalis), as well as to the brainstem and the spinal cord, and various intrahypothalamic projections. Our identification of a strong somatostatinergic pathway from the lateral and ventral part of the CG to the PnC adds another item to this list. It must be noted that somatostatin should be viewed as a cotransmitter and that the physiological properties of these pathways are

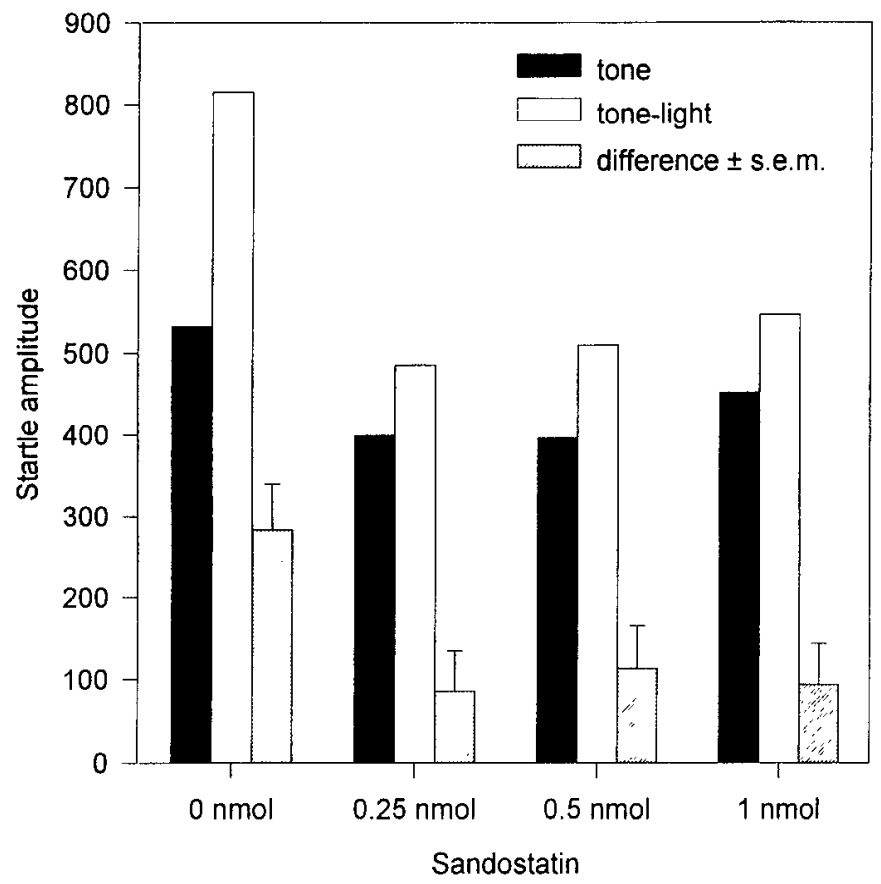

Figure 5. Bar diagram showing the effects on fear-potentiated startle of local microinjections of sandostatin (or saline) into the $\mathrm{PnC}$. The mean ASR amplitudes (arbitrary units) in the absence (black bars) and presence (white bars) of the CS, and the difference scores ( \pm SEM, hatched bars) are plotted.

also determined by their classical transmitters. Although most of the classical transmitters have been identified in the CG, it presently is not clear which one is colocalized with somatostatin (Smith et al., 1994).

The acoustically responsive neurons in the $\mathrm{PnC}$ described in this study had the same physiological properties as the giant reticulospinal PnC neurons mediating the ASR (Ebert and Koch, 1992; Lingenhöhl and Friauf, 1992, 1994); therefore, we are confident that our electrophysiological data describe neurons that are relevant for the ASR. The microiontophoretical application of the somatostatin receptor agonist sandostatin had no effect on the baseline and tone-evoked activity of PnC neurons, but markedly attenuated the increase of neural activity seen after administration of glutamate. Five somatostatin receptor subtypes have been characterized, and mRNA for all of these receptor proteins is present in the PnC brainstem (Hoyer et al., 1994; Reisine and Bell, 1995). Sandostatin shows a high affinity to the sst-2, sst-3, and sst- 5 receptor, but a very low affinity to the sst -1 and sst -4 receptor (Hoyer et al., 1994). Somatostatin receptors have mainly inhibitory effects on neural activity, but excitatory effects have also been described (Hoyer et al., 1994; Reisine and Bell, 1995; Rubinow et al., 1995). Somatostatin also may act on the release of other transmitters, e.g., increase the release of dopamine, norepinephrine, acetylcholine, and serotonin, or decrease the release of histamine, glutamate, and norepinephrine in different brain nuclei (Rubinow et al., 1995). The present study revealed that sandostatin decreases the effect of glutamate on the activity of PnC neurons. This is consistent with previous work showing that somatostatin reduces the action of glutamate in the striatum ( $\mathrm{Ru}-$ binow et al., 1995).

Sandostatin injected into the PnC of awake animals influenced the ASR in a way strikingly compatible with its effect on the electrical activity of PnC neurons: sandostatin injections did not 
change the baseline ASR amplitude, corresponding to the fact that sandostatin had no effect on the tone-evoked activity of PnC neurons. However, sandostatin injections blocked fear potentiation of the ASR, probably because sandostatin reduced the increasing effects of glutamate on the tone-evoked activity of PnC neurons. The conception that glutamate in the $\mathrm{PnC}$ plays a role in the mediation of the effect of conditioned fear on the ASR has been proposed tentatively, based on the finding that the electrical stimulation of the amygdala increases the tone-evoked activity of PnC neurons (Koch and Ebert, 1993) and the preliminary finding that the enhancing effect of amygdala stimulation on the toneevoked activity of PnC neurons can be reduced by the NMDA receptor antagonist MK-801 (Koch and Ebert, 1992). Therefore, we speculated that the NMDA receptor mediates the slow and tonic excitation of the $\mathrm{PnC}$, which is mediated by the amygdala and might underlie the enhancement of the ASR by fear or anxiety. It is conceivable that these NMDA receptor-mediated effects on PnC neurons can be modulated by somatostatin.

The question is how the indirect pathway from the amygdala via the CG (Fendt et al., 1994) to the PnC interacts with the direct pathway from the amygdala (Rosen et al., 1991; Koch and Ebert, 1993) to the PnC. The CG sends a somatostatinergic projection to the $\mathrm{PnC}$ and itself receives somatostatinergic afferents from the amygdala (Inagaki et al., 1983; Gray and Magnuson, 1992). Assuming that somatostatin acts as an inhibitory transmitter in the $\mathrm{CG}$, it could be hypothesized that activity of the amygdala would inhibit the CG and this inhibition would then cause a disinhibition of the PnC. In other words, it could be speculated that the amygdala stimulates the PnC via a direct NMDA-mediated pathway and at the same time disinhibits the PnC by means of an indirect somatostatinergic pathway via the CG. These hypotheses will be addressed in future experiments.

One problem with the above assumption of a disinhibition of the $\mathrm{PnC}$ via the $\mathrm{CG}$ arises from the fact that lesions of the $\mathrm{CG}$ block fear-potentiated startle in our laboratory (Fendt et al., 1996), which is not compatible with the speculation that activation of the CG inhibits the PnC. However, not only is there the indirect somatostatinergic pathway from the central nucleus of the anyydala via the $\mathrm{CG}$ to the $\mathrm{PnC}$, but excitatory transmitters also exist within these pathways, and these other transmitters may be necessary for the fear potentiation of the ASR, so that lesions of the $\mathrm{CG}$ may also abolish this excitatory input to the $\mathrm{PnC}$. A possible candidate for one of the excitatory transmitters within this pathway is the neuropeptide cholecystokinin $(\mathrm{CCK})$, because a previous study from our laboratory (Fendt et al., 1995) showed that CCK has an increasing effect on the tone-evoked activity of PnC neurons and that $\mathrm{CCK}$ injections into the PnC enhance the ASR amplitude. However, the origin of the $\mathrm{CCK}$ projection to the $\mathrm{PnC}$ is presently unclear. Moreover, recent lesion studies have shown that lesions of the $\mathrm{CG}$ do not block fear-potentiated startle [albeit more rostral than the lesions of Fendt et al. (1996)] and that stimulation of the CG actually promotes fear potentiation (Walker and Davis, 1995). Obviously, further experimentation is necessary to resolve these controversies.

Based on the results of the present study, we extend our previously introduced hypothetical neural circuitry (Fendt et al., 1994; Krase et al., 1994; Fendt et al., 1996), which mediates the effects of conditioned fear: we assume that the amygdala is the locus of acquisition of conditioned fear. There are several paralle pathways from the central nucleus of the amygdala to the $\mathrm{PnC}$, which are all necessary for the expression of fear-potentiated startle. The ventral amygdalofugal pathway represents a direct projection without relay stations. The stimulation of this pathway increases the ASR (Rosen and Davis, 1988; Koch and Ebert, 1993), and lesions of this pathway block conditioned fear (Hitchcock and Davis, 1991). One of the transmitters of this pathway may be glutamate (Koch and Ebert, 1992, 1993). A second important route by which states of fear can be expressed is an indirect pathway from the amygdala via the CG (Fanselow, 1991; Graeff et al., 1993; Graeff, 1994; Kim et al., 1994) to the PnC. An important inhibitory transmitter of this pathway is somatostatin, and we hypothesize that excitatory transmitters also exist within this pathway. There are anatomical connections between the amygdala and the CG (Rizvi et al., 1991), and we assume that both the $\mathrm{CG}$ and the amygdala must be activated for the expression of fear. Therefore, lesions of the CG blocked potentiation of the ASR by conditioned and unconditioned fear (Fendt et al., 1994; Fendt et al., 1996). Expression of unconditioned fear can also be blocked by injections of substance $\mathrm{P}$ antagonists into the $\mathrm{PnC}$ (Krase et al., 1994), indicating that an indirect pathway from the amygdala via the laterodorsal tegmental nucleus to the $\mathrm{PnC}$ is involved in the potentiation of the ASR, because the laterodorsal tegmental nucleus is the only brain structure providing substance P-ergic input to the PnC (Kungel et al., 1994). In addition, Yeomans and coworkers (Yeomans and Pollard, 1993; Frankland and Yeomans, 1995; Frankland et al., 1995) showed a further indirect pathway from the amygdala to the brainstem or spinal cord via the rostrolateral midbrain, where lesions blocked the expression of fear-potentiated startle. The transmitters of this projection are presently not known.

We assume that for the expression of fear-potentiated startle, all these pathways must be intact, i.e., fear potentiation reflects the output of an interactive network between these different brain nuclei, so that destruction of only one part of this network impairs the function of the whole system.

\section{REFERENCES}

Davis M, Gendelman DS, Tischler MD, Gendelman PM (1982) A primary acoustic startle circuit: lesion and stimulation studies. J Neurosci 2:791-805.

Davis M (1992a) The role of the amygdala in fear-potentiated startle: implications for animal models of anxiety. Trends Pharmacol Sci 13:35-41.

Davis M (1992b) The role of the amygdala in fear and anxiety. Annu Rev Neurosci 15:353-375.

Davis M, Falls WA, Campeau S, Kim M (1993) Fear-potentiated startle: a neural and pharmacological analysis. Behav Brain Res 58:175-198.

Ebert U, Koch M (1992) Glutamate receptors mediate acoustic input to the reticular brain stem. NeuroReport 3:429-432.

Fanselow MS (1991) The midbrain periaqueductal gray as a coordinator of action in response to fear and anxiety. In: The midbrain periaqueductal gray matter (Depaulis A, Bandler R, eds), pp 151-173. New York: Plenum.

Fendt M, Koch M, Schnitzler H-U (1994) Lesions of the central gray block the sensitization of the acoustic startle response in rats. Brain Res 661:163-173.

Fendt M, Koch M, Kungel M, Schnitzler H-U (1995) Cholecystokinin enhances the acoustic startle response in rats. NeuroReport 6:2081-2084.

Fendt M, Koch M, Schnitzler H-U (1996) Lesions of the central gray block conditioned fear as measured with the potentiated startle paradigm. Behav Brain Res 74:127-134.

Frankland PW, Yeomans JS (1995) Fear-potentiated startle and electrically evoked startle mediated by synapses in rostrolateral midbrain. Behav Neurosci 109:669-680.

Frankland PW, Scott BW, Yeomans JS (1995) Axons and synapses mediating electrically evoked startle: collision tests and latency analysis. Brain Res 670:97-111. 
Graeff FG (1994) Neuroanatomy and neurotransmitter regulation of defensive behaviors and related emotions in mammals. Braz J Med Biol Res 27:811-829.

Graeff FG, Silveira MCL, Nogueira RL, Audi EA, Oliveira RMW (1993) Role of the amygdala and periaqueductal gray in anxiety and panic. Behav Brain Res 58:123-131.

Gray TS, Magnuson DJ (1992) Peptide immunoreactive neurons in the amygdala and the bed nucleus of the stria terminalis project to the midbrain central gray in the rat. Peptides 13:451-460.

Hitchcock JM, Davis M (1991) The efferent pathway of the amygdala involved in conditioned fear as measured with the fear-potentiated startle paradigm. Behav Neurosci 105:826-842.

Hoyer D, Lübbert H, Bruns C (1994) Molecular pharmacology of somatostatin receptors. Naunyn Schmiedebergs Arch Pharmacol 350:441-453.

Inagaki S, Kawai Y, Matsuzaki T, Shiosaka S, Tohyanna M (1983) Precise terminal fields of the descending somatostatinergic neuron system from the amygdaloid complex of the rat. J Hirnforsch 24:345-356.

Kim JJ, Rison RA, Fanselow MS (1994) Effects of amygdala, hippocampus, and periaqueductal gray lesions on short- and long-term contextual fear. Behav Neurosci 107:1088-1092.

Koch M, Ebert U (1992) Enhancement of auditory responses of pontine reticular brainstem neurons by glutamate and stimulation of the amygdaloid complex. Eur J Neurosci 5:142.

Koch M, Ebert U (1993) Enhancement of the acoustic startle response by stimulation of an excitatory pathway from the central amygdala/basal nuclcus of Meynert to the pontine reticular formation. Exp Brain Res 93:231-241.

Koch M, Lingenhöhl K, Pilz PKD (1992) Loss of the acoustic startle response following neurotoxic lesions of the caudal pontine reticular formation: possible role of giant neurons. Neuroscience 49:617-625.

Koch M, Kungel M, Herbert H (1993) Cholinergic neurons in the pedunculopontine tegmental nucleus are involved in the mediation of prepulse inhibition of the acoustic startle response in the rat. Exp Brain Res 97:71-82.

Krase W, Koch M, Schnitzler H-U (1994) Substance P is involved in the sensitization of the acoustic startle response by footshocks in rats. Behav Brain Res 63:81-88.

Kungel M, Friauf E (1995) Somatostatin and leu-enkephalin in the rat auditory brainstem during fetal and postnatal development. Anat Embryol (Berl) 191:425-443.

Kungel M, Ebert U, Herbert H, Ostwald J (1994) Substance P and other putative transmitters modulate the activity of reticular pontine neurons: an electrophysiological and immunohistochemical study. Brain Res 643:29-39.

Lingenhöhl K, Friauf E (1992) Giant neurons in the caudal pontine reticular formation receive short latency acoustic input: an intracellular recording and HRP-study in the rat. J Comp Neurol 325:473-492.

Lingenhöhl K, Friauf E (1994) Giant neurons in the rat reticular formation: a sensorimotor interface in the elementary acoustic startle circuit? J Neurosci 14:1176-1194.

Palkovits M, Brownstein MJ (1985) Distribution of neuropeptides in the central nervous system using biochemical micromethods. In: Handbook of chemical neuroanatomy, Vol 4, GABA and neuropeptides in the CNS, Part I (Björklund A, Hökfelt T, eds), pp 1-71. New York: Elsevier.

Paxinos G, Watson C (1986) The rat brain in stereotaxic coordinates. Sydney: Academic.

Reisine T, Bell GI (1995) Molecular properties of somatostatin receptors. Neuroscience 67:777-790.

Rizvi TA, Ennis M, Behbehani M, Shipley MT (1991) Connections between the central nucleus of the amygdala and the midbrain periaqueductal gray: topography and reciprocity. J Comp Neurol 303:121-131.

Rosen JB, Davis M (1988) Enhancement of acoustic startle by electrical stimulation of the amygdala. Behav Neurosci 102:195-202.

Rosen JB, Hitchcock JM, Sananes CB, Miserendino MJD, Davis M (1991) A direct projection from the central nucleus of the amygdala to the acoustic startle pathway: anterograde and retrograde tracing studies. Behav Neurosci 105:817-825.

Rubinow DR, Davis CL, Post RM (1995) Somatostatin in the central nervous system. In: Psychopharmacology: the fourth generation of progress (Bloom FE, Kupfer DJ, eds), pp 553-562. New York: Raven.

Shammah-Lagnado SJ, Negrao N, Silva BA, Ricardo JA (1987) Afferent connections of the nuclei reticularis pontis oralis and caudalis: a horseradish peroxidase sudy in the rat. Neuroscience 20:961-989.

Smith GST, Savery D, Marden C, Costa JJL, Averill S, Priestley JV, Rattray M (1994) Distribution of messenger RNAs encoding enkephalin, substance $P$, somatostatin, galanin, vasoactive intestinal polypeptide, neuropeptide $\mathrm{Y}$, and calcitonin gene-related peptide in the midbrain periaqueductal grey in the rat. J Comp Neurol 350:23-40.

Walker DL, Davis M (1995) Involvement of the periaqueductal gray in fear-potentiated startle. Soc Neurosci Abstr 760:16.

Yeomans JS, Pollard BA (1993) Amygdala efferents mediating electrically evoked startle-like responses and fear potentiation of acoustic startle. Behav Neurosci 107:596-610. 